\title{
Optic Nerve Hypoplasia: A Retrospective Analysis of Clinical Presentation and Disease Severity
}

This article was published in the following Dove Press journal:

Clinical Ophthalmology

\author{
Audrey N Netzel' \\ Robin High ${ }^{2}$ \\ Donny W Suh $\mathbb{D}^{3}$ \\ 'Creighton University School of \\ Medicine, Omaha, Nebraska, USA; \\ ${ }^{2}$ University of Nebraska Medical Center \\ College of Public Health, Omaha, \\ Nebraska, USA; ${ }^{3}$ Children's Hospital and \\ Medical Center of Omaha, Omaha, \\ Nebraska, USA
}

Purpose: Through the establishment of relationships between optic nerve hypoplasia $(\mathrm{ONH})$, optical coherence tomography (OCT) spectralis retinal nerve fiber layer (RNFL) thickness results and clinical sequelae, this study aims to identify long-term outcomes for individuals with $\mathrm{ONH}$.

Methods: A retrospective review of pediatric ophthalmology patients at Children's Hospital of Omaha from January 2000 to October 2018 was performed. All patients with ONH evaluated with Heidelberg Engineering's OCT Spectralis were identified. Patient records were investigated for visual acuity, presence of nystagmus, strabismus, and endocrinopathies. Statistical analysis with linear regression models, random intercepts models, and odds ratios were used to define relationships between RNFL thickness at the optic nerve head, nystagmus, strabismus, and endocrine dysfunction.

Results: There exists a strong trend of worsening visual acuity as RNFL thickness at the optic nerve head decreases in all scanned regions. This is strongest at the temporal-superior $(p=0.009)$ and nasal-inferior $(p=0.006)$ regions in patients with bilateral ONH. There is insufficient evidence of a difference in prevalence of nystagmus or strabismus between subjects with unilateral or bilateral ONH. Endocrinopathy is present in $21.6 \%$ of the subjects, with no statistical difference in the type of endocrinopathy or laterality of $\mathrm{ONH}$.

Conclusion: Trends established indicate that best-corrected visual acuity is related to RNFL thickness at the optic nerve head. Odds ratios for the prevalence of nystagmus also point to RNFL thickness as a contributing factor. These trends may have the potential to characterize ONH severity by objective measurement of clinical outcomes and RNFL thickness at the optic nerve head.

Keywords: optic nerve hypoplasia, optical coherence tomography, retinal nerve fiber layer thickness

\section{Introduction}

Optic nerve hypoplasia $(\mathrm{ONH})$, the most common of congenital optic disc anomalies, is a non-progressive, underdevelopment of the optic nerve. ${ }^{1,2}$ Whether unilateral or bilateral, defining characteristics of ONH include a small, often pale, disc accompanied by a peripapillary double-ring sign, thinning of the optic nerve fiber layer, and vascular tortuosity. ${ }^{2}$ Studies have documented that the incidence of $\mathrm{ONH}$ has risen from 1.8 per 100,000 affected individuals in $1977^{3}$ to 10.9 per 100,000 affected in $2006{ }^{4}$ Because of rising incidence, it is becoming increasingly important that clinicians understand the associated abnormalities and long-term outcomes for patients with $\mathrm{ONH}$.

It is well documented that $\mathrm{ONH}$ is associated with endocrinopathies, central nervous system (CNS) abnormalities, significant refractive errors, and developmental delay. ${ }^{2,5,8,12}$
Children's Hospital and Medical Center of

Omaha, Omaha, Nebraska, USA

Email dsuh@childrensomaha.org 
The American Association of Pediatric Ophthalmology and Strabismus recommends that all patients diagnosed with $\mathrm{ONH}$ receive an MRI and endocrine evaluation at the time of diagnosis because of the high incidence of abnormalities associated with $\mathrm{ONH}$ and the unpredictable inheritance pattern of these sequelae. Qian et al determined that abnormal MRI findings in children with $\mathrm{ONH}$ lack the sensitivity to predict endocrinopathies; however, normal MRI findings are also unable to rule out the presence of endocrine abnormalities. ${ }^{8}$ This same study suggested that a higher incidence of endocrinopathy was associated with bilateral $\mathrm{ONH}$ as compared to unilateral $\mathrm{ONH}$, but that the laterality of $\mathrm{ONH}$ could not reliably predict the degree of endocrinopathy present. ${ }^{8}$ There is no consensus on which endocrine abnormalities are most common in patients with $\mathrm{ONH}$. One study concluded that the most common endocrinopathy associated with $\mathrm{ONH}$ was a deficiency of adrenocorticotropic hormone (ACTH). ${ }^{8}$ Other studies asserted that the most common endocrinopathies in patients with ONH were growth hormone deficiency, central hypothyroidism, and central diabetes insipidus. ${ }^{9,10}$ Regardless of the most prevalent endocrinopathy, all were associated with developmental delays. Garcia-Filion et al identified $71 \%$ of the subjects with $\mathrm{ONH}$ as having a developmental delay at 5 years of age with increased likelihood of a developmental delay for those children with bilateral $\mathrm{ONH}$ as compared to those with unilateral ONH. ${ }^{5}$ Poor visual acuity was also associated with greater developmental delay. $^{5}$

The diagnosis of ONH remains primarily clinical, with no universal guidelines for laboratory or radiographic tests to establish a diagnosis. Because of this, optic nerve hypoplasia patients may mistakenly be labeled with alternative disease states, including optic atrophy. ${ }^{2}$ Although severe cases of $\mathrm{ONH}$ are often easily diagnosed, subtle presentations can be difficult to diagnose clinically. Current diagnostic standards for $\mathrm{ONH}$ include comparing a disc to macula (DM) and disc diameter (DD) ratio against that of the general population. Yet this DM:DD ratio varies with age, race, and gender. ${ }^{6}$ Most clinicians believe that neither this DM:DD ratio, nor other clinical signs (e.g., double-ring sign, vascular signs) are pathognomonic for $\mathrm{ONH}^{2}$ Thus, diagnosing and rating severity of $\mathrm{ONH}$ is difficult. The application of Optical Coherence Tomography (OCT) Spectralis to evaluate for the retinal nerve fiber layer (RNFL) thickness at the optic nerve head and to determine severity of $\mathrm{ONH}$ may improve consistency of diagnosis.
By establishing specific relationships between optic nerve hypoplasia, OCT Spectralis RNFL thickness results and clinical sequelae, this pilot study aims to identify longterm outcomes for individuals diagnosed with ONH. Correlation between OCT Spectralis results and subjects' best-corrected vision, presence or absence of nystagmus and strabismus, and number of associated endocrinopathies will better guide clinicians toward anticipating and treating disorders of optic nerve hypoplasia.

\section{Methods}

Subjects

A retrospective review of pediatric ophthalmology patients seen at Children's Hospital and Medical Center of Omaha from January of 2000 to October of 2018 was performed. All patients with a documented diagnosis of Optic Nerve Hypoplasia (ONH) who were evaluated with Heidelberg Engineering's Optical Coherence Tomography (OCT) Spectralis were identified. Selection inclusion criteria for this study included successful completion of OCT Spectralis imaging by the patient as well as a medical record containing documentation of at least one eye exam identifying the patient's best-corrected visual acuity and the presence or absence of nystagmus, strabismus, and endocrinopathy. Children who were diagnosed with $\mathrm{ONH}$ clinically but were unable to undergo successful OCT imaging were excluded from this study. Data abstracted from the medical records included patient date of birth, gender, race, age at diagnosis of $\mathrm{ONH}$, unilateral or bilateral $\mathrm{ONH}$, endocrine lab work, ocular examination findings, and Heidelberg OCT Spectralis results. University of Nebraska Medical Center (UNMC) Institutional Review Board (IRB) granted ethical approval for this study. This IRB also waived the requirement for investigators to obtain patient and parental consent to review participating children's medical records. During this retrospective analysis, patient data remained confidential in compliance with HIPAA regulations and the Declaration of Helsinki.

An experienced pediatric ophthalmologist diagnosed $\mathrm{ONH}$ based on the dilated fundoscopic exam of the patient and documented the presence of nystagmus or strabismus at any point during the patient's life. The patient's initial visual acuity and best-corrected vision by October of 2018 were recorded. Patient visual acuity was measured by Snellen recognition or Teller cards, as was appropriate for the child's age and developmental stage. Endocrinopathy 
was identified by hormone function tests and patient use of hormone replacement therapy.

Heidelberg OCT Spectralis was used to measure the retinal nerve fiber layer (RNFL) thickness of the optic nerve head via peripapillary circular scanning in eyes of patients diagnosed clinically with ONH. Classification of the RNFL thickness as "normal," "borderline," and "outside normal limits," corresponds to eyes that fall within the 5 th to 95 th percentiles, 1 st to 5 th percentiles, and $<1$ st percentile, respectively, of the normative database provided by the Heidelberg software. This normative database was developed from healthy subjects of Caucasian origin. ${ }^{11}$ Data for RNFL thickness were reported as measured thickness at specific locations, or domains, on the optic nerve head of temporal-superior (TS), temporal (T), temporal-inferior (TI), nasal-inferior (NI), nasal $(\mathrm{N})$, nasal-superior (NS), and global (G).

\section{Statistical Analysis}

Univariate analyses (means, medians, standard deviations, etc.) were conducted on all variables which were also assessed for the presence of outliers and missing data.

The best-corrected visual acuity data were recorded as a response variable divided into five ordinal categories (see Figure 1) and here could only be evaluated with a statistical model that assumes continuous values. The OCT data from the seven regions were consistently rightskewed. Visual acuity was assessed with a linear regression model that computes slopes as a function of the OCT data separately for subjects with unilateral and bilateral $\mathrm{ONH}$. To reduce the leverage of a few large values of the OCT data on the regression slopes, a log transformation was applied. A random intercepts model was also applied to account for the correlations due to multiple observations collected from each subject on both the right and left eyes. The GLIMMIX procedure from SAS/STAT software, version 9.4 (C) 2002-2012) of the SAS System for Windows (Cary, NC), was utilized for these analyses.

Nystagmus and Strabismus were evaluated as dichotomous responses (present/absent) with odds ratios computed from exact logistic regression models. The relatively small sample size indicated models based on exact computations are appropriate here. The presence of Nystagmus was evaluated with the OCT data. Since most subjects have developed Strabismus (32 out of 37), statistical models for its presence based on the thickness of the RNFL at the scan angles did not converge to a reasonable solution.
All computations were made with the LOGISTIC procedure from SAS/STAT software.

\section{Results}

Characteristics of the study subjects are reported in Table 1. Of the 37 patients identified with $\mathrm{ONH}$ and recorded Heidelberg OCT Spectralis results, 22 subjects demonstrated bilateral $\mathrm{ONH}$ and 15 subjects had unilateral $\mathrm{ONH}$, for a total of 59 eyes affected. Because some participants attempted multiple OCT scans during their treatment at Children's Hospital of Omaha, a total of 82 eyes met study inclusion criteria. Of the 82 eyes, 17 eyes did not successfully complete OCT testing and were excluded from any analysis comparing bestcorrected visual acuity, nystagmus, or strabismus to OCT results. Out of these 17 eyes excluded from the study, 3 eyes were from patients with unilateral ONH. Patients were between the ages of 5 and 19 years of age at the time of diagnosis and OCT testing. And, $75.6 \%$ of subjects identified as Caucasian/White.

\section{Best-Corrected Visual Acuity}

Evaluation of the relationship between RNFL thickness at the optic nerve head and a subject's best-corrected visual acuity demonstrated a strong trend of worsening visual acuity as RNFL thickness decreased for all scan angles (G, N, NI, NS, T, TI, TS; Figure 1). The degree of negativity in slopes for Figure 1 was logarithmically transformed for statistical analysis and documented in Table 2 as the log coefficient. These non-zero values represent the trends in visual acuity as scan angle values change. R-squared values for Figure 1 are not reported because RNFL thickness values across the $\mathrm{x}$-axis are computed on a log scale. Although the logged RNFL thickness values themselves are linear and can have an r-square, there is no natural interpretation of this result in terms of the original data. Additionally, with several subjects having two or more observations plotted in Figure 1 - the reason for using a random effect in the computation - r-square is not a typical output summary measure as would be expected with a linear regression equation. Statistically significant relationships between RNFL thickness and best-corrected visual acuity were present in the nasalinferior $(p=0.006)$ and temporal-superior $(p=0.009)$ domains in subjects with bilateral $\mathrm{ONH}$, as well as in the global $(\mathrm{p}=0.006)$, nasal-inferior $(\mathrm{p}=0.022)$, temporalinferior $(\mathrm{p}=0.001)$, and temporal-superior $(\mathrm{p}=0.021)$ domains in subjects with unilateral $\mathrm{ONH}$. 


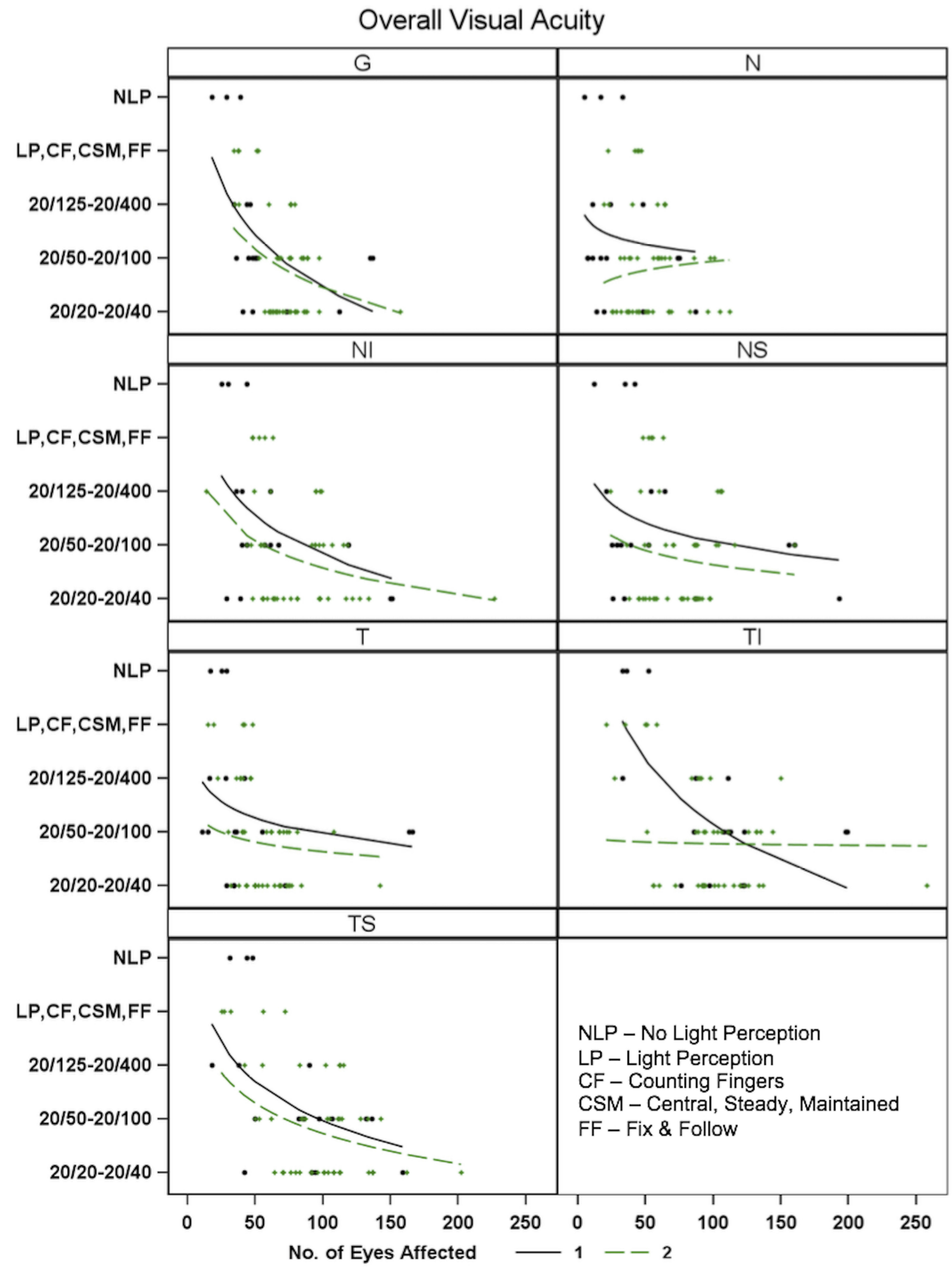

Figure I Retinal nerve fiber layer (RNFL) thickness $(\mu \mathrm{m})$ at optic nerve head as compared to best-corrected visual acuity in subjects with unilateral and bilateral optic nerve hypoplasia. 
Table I Characteristics of Subjects

\begin{tabular}{|l|l|l|}
\hline Characteristic & $\%$ & $\mathbf{n} / \mathbf{N}$ \\
\hline Gender & & \\
Male & $57 \%$ & $21 / 37$ \\
Female & $43 \%$ & $16 / 37$ \\
\hline Race or Ethnicity & & \\
White/Caucasian & $76 \%$ & $28 / 37$ \\
African-American & $11 \%$ & $4 / 37$ \\
Hispanic & $8 \%$ & $3 / 37$ \\
American Indian & $3 \%$ & $1 / 37$ \\
Other & $3 \%$ & $1 / 37$ \\
\hline Laterality of ONH & & \\
Unilateral & $41 \%$ & $15 / 37$ \\
Bilateral & $59 \%$ & $22 / 37$ \\
\hline Endocrinopathies & & \\
GH deficiency & $11 \%$ & $4 / 37$ \\
Hypothyroidism & $11 \%$ & $4 / 37$ \\
Adrenal insufficiency & $19 \%$ & $7 / 37$ \\
Testosterone deficiency & $3 \%$ & $1 / 37$ \\
\hline
\end{tabular}

\section{Nystagmus and Strabismus}

For patients with multiple visits, the presence or absence of nystagmus remained unchanged. There were three patients that developed strabismus between their initial visit and follow-up visits. For these patients, the presence or absence of strabismus was determined by the most recent visit (Table 3).

Overall, $29.7 \%$ of subjects in this study have nystagmus. Twenty percent of the subjects have nystagmus and unilateral ONH as compared to $36.4 \%$ of the subjects having bilateral $\mathrm{ONH}$ and nystagmus. The exact Pearson chi-square p-value for this difference of $16.4 \%$ between those with unilateral and bilateral $\mathrm{ONH}$ is $\mathrm{p}=0.47$, indicating that there is insufficient evidence of a difference in the presence of nystagmus between patients with unilateral versus bilateral $\mathrm{ONH}$.

Table 4 and Figure 2 evaluate the odds of a patient with nystagmus given a measured RNFL thickness of the optic nerve head by OCT Spectralis. These results are based on exact logistic regression methods. Odds ratios are reported in units of 10 for the RNFL thickness at the scanned region. That is, they indicate what would occur with a 10-point increase in the RNFL thickness at the specified location for the magnitude of the increase or decrease in the probability of having nystagmus. Given the relatively small sample size in this study, the results of the calculated odds ratio indicate possible patterns that may be expected, but not guaranteed, in patients with optic nerve hypoplasia. The odds ratio calculated for each scanned region indicates the likelihood

Table 2 Evaluation of Relationship Between RNFL Thickness of the Optic Nerve Head, as Determined by OCT Spectralis, for Subjects with Either Unilateral or Bilateral $\mathrm{ONH}$, and Recorded Best-Corrected Visual Acuity

\begin{tabular}{|c|c|c|c|c|c|c|}
\hline \multicolumn{2}{|c|}{ Parameter Estimates } & \multirow[t]{2}{*}{ Log Coefficient } & \multirow[t]{2}{*}{ Standard Error } & \multirow[t]{2}{*}{ Lower } & \multirow[t]{2}{*}{ Upper } & \multirow[t]{2}{*}{ P-value } \\
\hline Spectral Domain & Eyes Involved & & & & & \\
\hline \multirow[t]{2}{*}{ G } & Unilateral & -1.42 & 0.49 & -2.41 & -0.43 & $0.006 * *$ \\
\hline & Bilateral & -1.04 & 0.51 & -2.08 & 0.01 & 0.052 \\
\hline \multirow[t]{2}{*}{$\mathrm{NI}$} & Unilateral & -1.07 & 0.45 & -1.97 & -0.16 & $0.022 *$ \\
\hline & Bilateral & -0.73 & 0.25 & -1.25 & -0.22 & $0.006 * *$ \\
\hline \multirow[t]{2}{*}{ NS } & Unilateral & $-0.5 \mathrm{I}$ & 0.34 & -1.21 & 0.19 & 0.14 \\
\hline & Bilateral & -0.39 & 0.38 & -1.15 & 0.38 & 0.31 \\
\hline \multirow[t]{2}{*}{ N } & Unilateral & -0.24 & 0.31 & -0.88 & 0.4 & 0.45 \\
\hline & Bilateral & 0.24 & 0.27 & -0.32 & 0.8 & 0.38 \\
\hline \multirow[t]{2}{*}{ TI } & Unilateral & -1.73 & 0.5 & -2.74 & $-0.7 \mid$ & $0.001 * *$ \\
\hline & Bilateral & -0.04 & 0.35 & -0.76 & 0.67 & 0.9 \\
\hline \multirow[t]{2}{*}{ TS } & Unilateral & -1.04 & 0.43 & -1.91 & -0.17 & $0.021^{*}$ \\
\hline & Bilateral & -0.8 & 0.29 & -1.39 & -0.21 & $0.009 * *$ \\
\hline \multirow[t]{2}{*}{$\mathrm{T}$} & Unilateral & -0.44 & 0.4 & -1.26 & 0.38 & 0.28 \\
\hline & Bilateral & -0.26 & 0.29 & -0.85 & 0.33 & 0.37 \\
\hline
\end{tabular}

Notes: Lower and Upper refer to the $95 \%$ confidence interval for the coefficient. *Indicates a statistically significant result $(\mathrm{p}<0.05)$ and $* *$ Indicates a highly statistically significant result $(\mathrm{p}<0.01)$. 
Table 3 Summary of Subjects with Nystagmus, Strabismus at Most Recent Office Visit, and Endocrinopathies According to the Laterality of the Optic Nerve Hypoplasia

\begin{tabular}{|c|c|c|c|c|c|}
\hline & \multirow[t]{2}{*}{ Total } & Unilateral ONH & Bilateral ONH & Unilateral ONH & Bilateral ONH \\
\hline & & $\mathbf{N}$ & $\mathbf{N}$ & $\%$ & $\%$ \\
\hline \multicolumn{6}{|l|}{ Nystagmus } \\
\hline Absent & 26 & 12 & 14 & 80 & 63.6 \\
\hline Present & 11 & 3 & 8 & 20 & 36.4 \\
\hline \multicolumn{6}{|l|}{ Strabismus } \\
\hline Absent & 5 & 1 & 4 & 6.7 & 18.2 \\
\hline Present & 32 & 14 & 18 & 93.3 & 81.8 \\
\hline \multicolumn{6}{|c|}{ Growth Hormone (IGF I) } \\
\hline Too low & 4 & 2 & 2 & 18.2 & 15.4 \\
\hline Normal & 20 & 9 & 11 & 81.8 & 84.6 \\
\hline Undetermined & 13 & 4 & 9 & & \\
\hline \multicolumn{6}{|c|}{ Thyroid Function } \\
\hline Too low & 4 & 2 & 2 & 18.2 & 11.8 \\
\hline Normal & 24 & 9 & 15 & 81.8 & 88.2 \\
\hline Undetermined & 9 & 4 & 5 & & \\
\hline \multicolumn{6}{|l|}{ Cortisol } \\
\hline Too low & 7 & 2 & 5 & 18.2 & 38.5 \\
\hline Normal & 17 & 9 & 8 & 81.8 & 61.5 \\
\hline Undetermined & 13 & 4 & 9 & & \\
\hline \multicolumn{6}{|l|}{ Testosterone } \\
\hline Too low & I & 1 & & 50 & \\
\hline Normal & 4 & 1 & 3 & 50 & 100 \\
\hline Undetermined & 32 & 13 & 19 & & \\
\hline
\end{tabular}

Note: "Undetermined" values indicate subjects for which blood hormone levels were ordered, but never drawn.

of seeing nystagmus, given an increasing value of RNFL thickness at that location. That all odds ratios are less than 1.00 with negative coefficients, except at the nasal location, indicates that for increasing RNFL thickness, the likelihood of nystagmus decreases. None of the coefficients are

Table 4 Estimation of the Effects of RNFL Thickness at Optic Nerve Head Domains in the Presence of Nystagmus

\begin{tabular}{|c|c|c|c|c|}
\hline \multirow{2}{*}{$\begin{array}{l}\text { Parameter } \\
\text { Estimates }\end{array}$} & \multirow[t]{3}{*}{ Coefficient } & Standard & \multirow[t]{3}{*}{ P-value } & \multirow{3}{*}{$\begin{array}{l}\text { Odds } \\
\text { Ratio }\end{array}$} \\
\hline & & \multirow{2}{*}{ Error } & & \\
\hline Effect & & & & \\
\hline G & -0.0097 & 0.016 & 0.58 & 0.908 \\
\hline $\mathrm{NI}$ & -0.0092 & 0.011 & 0.42 & 0.912 \\
\hline NS & 0.00 & 0.010 & 0.96 & 1.00 \\
\hline $\mathrm{N}$ & 0.0109 & 0.0139 & 0.43 & 1.011 \\
\hline TI & -0.0114 & 0.0113 & 0.32 & 0.9887 \\
\hline TS & -0.0172 & 0.0112 & 0.11 & 0.983 \\
\hline $\mathrm{T}$ & -0.0076 & 0.0146 & 0.66 & 0.9924 \\
\hline
\end{tabular}

Notes: Laterality of OCT Spectralis results is not considered. Odds ratios are in units of 10; that is, a 10-point increase in the RNFL thickness indicates the magnitude of the increase or decrease in the occurrence of an event. statistically significant here $(\mathrm{p}<0.05)$, although 6 of the 7 slopes of the scanned regions are negative, indicating the expected direction of the effect as described above. The odds of a patient with nystagmus given a measured RNFL thickness of the optic nerve head by OCT Spectralis can also be isolated by right (OD) and left (OS) eye measurements (Table 5). These results are based on exact logistic regression methods with different slopes of the coefficient for each eye. Although most coefficients are not significant, several of the scan angles OD have a positive coefficient with an associated OS coefficient that is negative.

Additionally, in this study, $86.5 \%$ of the subjects have a history of strabismus. And, $93.3 \%$ of the subjects with unilateral $\mathrm{ONH}$ have strabismus, as compared to $81.8 \%$ of the subjects with bilateral ONH. The exact Pearson chisquared p-value for this difference of $11.5 \%$ between unilateral and bilateral $\mathrm{ONH}$ with strabismus is $\mathrm{p}=0.39$, indicating there is insufficient evidence of a difference between patients with unilateral and bilateral $\mathrm{ONH}$ when considering the likelihood of developing strabismus. 


\section{Odds Ratios for Nystagmus}
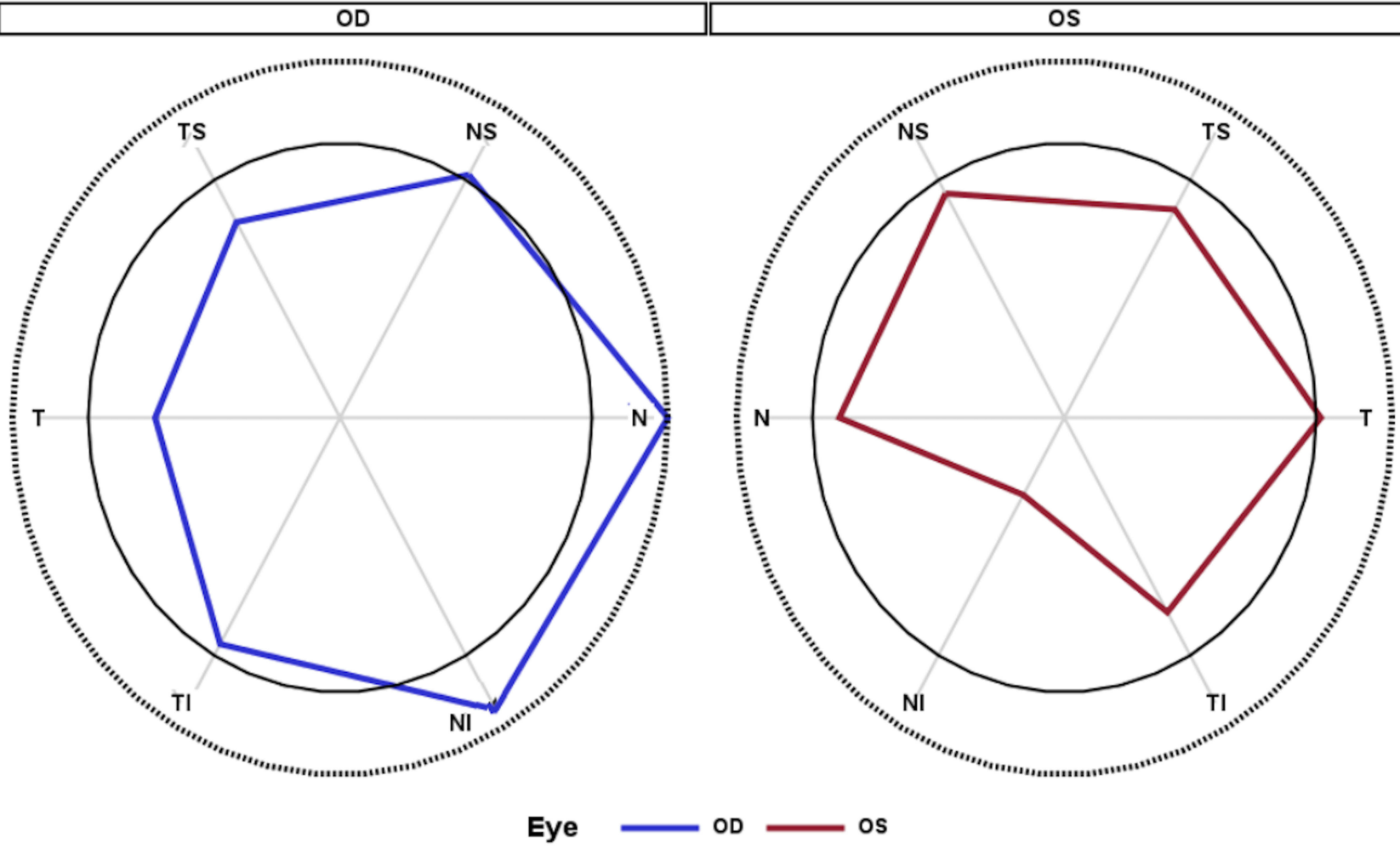

Eye

OD

os

Parameters: TS T TI NI N NS

Figure 2 Radar graph depiction of the odds ratio of having nystagmus evaluated at individual optic nerve head regions. In each panel, the outer gray circle represents the maximum value across all the points; the black circle represents an odds ratio of I (i.e., no difference). Values within the black circle have an odds ratio of less than I. Right eye: OD; Left eye: OS. Optic nerve head regions include temporal-superior (TS), temporal (T), temporal-inferior (TI), nasal-inferior (NI), nasal (N), and nasal-superior (NS).

\section{Endocrine Function}

Table 3 reports percentages of subjects with endocrine dysfunction as evidenced by abnormal levels of IGF-1, TSH, cortisol, or testosterone. This table also indicates the amount of missing data for endocrine function secondary to poor patient follow-up. Overall, $21.6 \%$ of the subjects in this study have endocrine dysfunction. Of those with endocrine dysfunction $3 / 8(37.5 \%)$ have unilateral ONH and 5/8 (62.5\%) have bilateral ONH. Subjects with multiple endocrine abnormalities may have either unilateral $(2 / 4)$ or bilateral $(2 / 4) \mathrm{ONH}$. The most common endocrine abnormality observed in this subject group is low cortisol (7/8 subjects). Given the small sample size, no conclusions can be made about the relationship between the severity of endocrine dysfunction and best-corrected visual acuity or OCT Spectralis results.

\section{Discussion}

There exists large variation in the best-corrected visual acuity maintained by people with optic nerve hypoplasia, extending from 20/20 vision to no light perception (NLP) in the affected eye. Because of this large range, historically it has been difficult for ophthalmologists to predict a patient's visual acuity given clinically derived parameters for disease diagnosis (e.g., DM:DD ratio). In the past, the degree of disease severity has also been unclearly defined - some consider this best measured by the degree of optic nerve fiber thinning or DM:DD ratio, while others characterize it through clinical outcomes, such as visual acuity. ${ }^{2,5,7}$ This study demonstrates a new option for characterizing ONH severity and correlated best-corrected visual acuity through the measurement of the retinal nerve fiber layer thickness at the optic nerve head. In multiple optic nerve head regional domains (G, NI, TI, and TS specifically) statistically significant log coefficients were identified. A p-value $<0.05$ indicates the slope of the line, as calculated by regression, is significantly different from zero. Thus, with negative log coefficients, as RNFL thickness increases, visual acuity improves. A log coefficient of zero would indicate no relationship between the scanned region and best-corrected visual acuity. 
Table 5 Estimation of the Effects of RNFL Thickness at Optic Nerve Head Domains in the Presence of Nystagmus

\begin{tabular}{|c|c|c|c|c|c|}
\hline \multicolumn{2}{|c|}{$\begin{array}{l}\text { Parameter } \\
\text { Estimates }\end{array}$} & \multirow[t]{2}{*}{ Coefficient } & \multirow[t]{2}{*}{$\begin{array}{l}\text { Standard } \\
\text { Error }\end{array}$} & \multirow[t]{2}{*}{ P-value } & \multirow[t]{2}{*}{$\begin{array}{l}\text { Odds } \\
\text { Ratio }\end{array}$} \\
\hline Effect & Values & & & & \\
\hline G & $\begin{array}{l}\text { OD } \\
\text { OS }\end{array}$ & $\begin{array}{l}0.005 \\
-0.023\end{array}$ & $\begin{array}{l}0.024 \\
0.027\end{array}$ & $\begin{array}{l}0.84 \\
0.41\end{array}$ & $\begin{array}{l}1.005 \\
0.977\end{array}$ \\
\hline $\mathrm{NI}$ & $\begin{array}{l}\text { OD } \\
\text { OS }\end{array}$ & $\begin{array}{l}0.021 \\
-0.112\end{array}$ & $\begin{array}{l}0.016 \\
0.067\end{array}$ & $\begin{array}{l}0.2 \\
0.006 * *\end{array}$ & $\begin{array}{l}1.021 \\
0.894\end{array}$ \\
\hline NS & $\begin{array}{l}\text { OD } \\
\text { OS }\end{array}$ & $\begin{array}{l}0.002 \\
-0.006\end{array}$ & $\begin{array}{l}0.011 \\
0.021\end{array}$ & $\begin{array}{l}0.81 \\
0.86\end{array}$ & $\begin{array}{l}1.002 \\
0.994\end{array}$ \\
\hline $\mathrm{N}$ & $\begin{array}{l}\text { OD } \\
\text { OS }\end{array}$ & $\begin{array}{l}0.026 \\
-0.011\end{array}$ & $\begin{array}{l}0.019 \\
0.025\end{array}$ & $\begin{array}{l}0.16 \\
0.7\end{array}$ & $\begin{array}{l}1.027 \\
0.989\end{array}$ \\
\hline $\mathrm{TI}$ & $\begin{array}{l}\text { OD } \\
\text { OS }\end{array}$ & $\begin{array}{l}-0.005 \\
-0.02\end{array}$ & $\begin{array}{l}0.015 \\
0.02\end{array}$ & $\begin{array}{l}0.74 \\
0.3\end{array}$ & $\begin{array}{l}0.995 \\
0.98\end{array}$ \\
\hline TS & $\begin{array}{l}\text { OD } \\
\text { OS }\end{array}$ & $\begin{array}{l}-0.02 \\
-0.013\end{array}$ & $\begin{array}{l}0.016 \\
0.016\end{array}$ & $\begin{array}{l}0.22 \\
0.41\end{array}$ & $\begin{array}{l}0.98 I \\
0.987\end{array}$ \\
\hline $\mathrm{T}$ & $\begin{array}{l}\text { OD } \\
\text { OS }\end{array}$ & $\begin{array}{l}-0.031 \\
0.002\end{array}$ & $\begin{array}{l}0.03 \\
0.016\end{array}$ & $\begin{array}{l}0.31 \\
0.81\end{array}$ & $\begin{array}{l}0.97 \\
1.002\end{array}$ \\
\hline
\end{tabular}

Notes: Right (OD) and left (OS) eyes are considered separately. Odds ratios are reported in units of 10; that is, a 10-point increase in the RNFL thickness indicates the magnitude of the increase or decrease in the occurrence of an event. **Indicates a highly statistically significant result $(p<0.0$ I).

The relationship between visual acuity and RNFL thickness at specific scanned regions was also compared for unilateral and bilateral ONH. For the scan angles of nasal-inferior and temporal-superior, subjects with both unilateral and bilateral $\mathrm{ONH}$ showed a statistically significant correlation of RNFL thickness and best-corrected visual acuity. In addition to these scan angles, in subjects with unilateral $\mathrm{ONH}$, the global and temporal-inferior regions also showed a significant correlation for RNFL thickness and bestcorrected visual acuity. The reason for these differences between unilateral and bilateral ONH, RNFL thickness, and visual acuity remain unclear. That only some, but not all optic nerve head regions have $\mathrm{p}$-values $<0.05$ could be the result of the small sample size. As such, the small sample size of this study best allows for interpretation of results as relationship trends. Amblyopic factors also likely contribute to unilateral and bilateral variation, as amblyopic loss is expected to decrease the visual potential in affected eyes of unilateral ONH patients. ${ }^{17}$ However, because amblyopic factors were not evaluated nor addressed in this study, conclusions as to their effect on unilateral and bilateral variation cannot be made here. Future studies addressing amblyopic factors and their effect on RNFL thickness and best-corrected visual acuity should be considered. A future study with a larger sample size is also likely to have greater power in differentiating these trends from statistically significant evidence.

The use of peripapillary circular scanning by the OCT Spectralis, as opposed to volume scanning, may also lead to the trends observed between RNFL thickness and bestcorrected visual acuity. The OCT Spectralis software used in this study evaluates RNFL thickness at a fixed radius. As such, a limitation of peripapillary scanning to identify RNFL thickness is that micro-disc results may not be as reliable as normal-sized disc results. ${ }^{11}$ Additionally, perfect alignment of Spectralis peripapillary circular scans can be difficult to achieve for patients with nystagmus. ${ }^{17}$ In this study, patients underwent multiple OCT peripapillary scans at a single office visit. From this collection of scans, a single scan identified to have the highest quality of image and OCT most centered on the optic nerve was chosen for use in this study. By limiting the incidence of misalignment for the scan, risk of variability to the sector analysis was reduced.

The observed trends of worsening best-corrected visual acuity with decreasing RNFL thickness may also be related to the reflective symmetry between the scan angles of nasalinferior and temporal-superior. For example, images viewed in the temporal-superior visual field will be detected by the nasal-inferior retina and transmitted through the optic nerve. The opposite, in which images appear in the nasal-inferior visual field and project onto the temporal-superior retina, can also be observed. Multiple studies have shown that there is a direct relationship between RNFL damage at the optic disc and such visual impairment. ${ }^{14,15}$

Although clinicians agree that nystagmus and strabismus are associated with $\mathrm{ONH}$, there is little consensus on the prevalence of either nystagmus or strabismus in this disease. Various studies have identified the percentage of patients with both $\mathrm{ONH}$ and nystagmus as between $10 \%$ and $86 \%$. ${ }^{7,11,13}$ Our study reports a prevalence of nystagmus at $29.7 \%$, which falls within previously reported ranges. Subjects with bilateral ONH were more likely to have nystagmus than those with unilateral $\mathrm{ONH}$; however, this difference was not statistically significant $(\mathrm{p}=0.47)$. Multiple other studies have also found that bilateral $\mathrm{ONH}$ is more highly associated with nystagmus. ${ }^{9,16}$

The presence of strabismus in patients with $\mathrm{ONH}$ has been reported between $27 \%$ and $50 \%{ }^{7,11,13}$ The prevalence of strabismus in our population is high above previously reported values at $86.5 \%$ of the subjects. The relatively small sample size may explain this variation in prevalence. 
Odds ratios for acquiring nystagmus, as derived from the RNFL thickness at individual optic nerve head scan regions of global $(\mathrm{G})$, nasal-inferior $(\mathrm{NI})$, nasal-superior (NS), nasal $(\mathrm{N})$, temporal-inferior (TI), temporal-superior (TS), and temporal (T), indicate that with increasing RNFL thickness the likelihood of nystagmus decreases. Although no odds ratios are statistically significant (Table 4), these results demonstrate a consistent trend of reduced nystagmus with increased RNFL thickness in all scanned regions except the nasal region. This result may be due to the small sample size of subjects available. Future studies with larger subject population may better elucidate if the positive coefficient at the nasal location is a true representation of increased odds of nystagmus with larger RNFL thickness, or merely an underpowered result.

Evaluation of this odds ratio for nystagmus with right and left eyes analyzed separately demonstrates a statistically significant coefficient at the nasal-inferior position of the left eye $(p=0.006)$. All other values are nonsignificant, but do demonstrate a trend between right and left eyes in which right eyes appear more likely to have positive coefficients and left eyes to have negative coefficients for their odds ratios. This may be the result of reflective symmetry between right and left eyes (e.g., nasal indicating a position on the right side of the optic nerve head in the left eye, but on the left side of the optic nerve head in the right eye). However, as this is an underpowered result, such directional aspects can occur here while not occurring in a study with a larger subject population. To our knowledge, no other studies have evaluated OCT RNFL thickness at a given scan angle and its relationship to the presence or absence of nystagmus.

Proper endocrine function is imperative for overall childhood development as well as in multiple developmental domains, including personal-social, motor, cognitive skills, adaptive communication, etc. ${ }^{5}$ Garcia-Filion et al reported hormonal dysfunction in $79 \%$ of subjects with optic nerve hypoplasia. ${ }^{5}$ This percentage is considerably higher than the percent of subjects with endocrinopathy (21.6\%) discovered in this study. There is currently no consensus on which endocrine abnormalities are most common in patients with ONH. One study concluded that the most common endocrinopathy associated with $\mathrm{ONH}$ was a deficiency of adrenocorticotropic hormone (ACTH). ${ }^{8}$ Other studies asserted that the most common endocrinopathies in patients with ONH were growth hormone deficiency, central hypothyroidism, and central diabetes insipidus. ${ }^{9,10}$ In this study, the most common endocrine dysfunction was adrenal insufficiency, affecting 19\% of the subjects with endocrinopathy. Growth hormone deficiency and hypothyroidism were also present in $11 \%$ of the subjects with endocrinopathy. Because of the limited number of subjects who were tested for testosterone deficiency, no conclusions can be made as to the prevalence of testosterone deficiency in this population.

Multiple studies have suggested that a higher incidence of endocrinopathy is associated with bilateral $\mathrm{ONH}$ as compared to unilateral $\mathrm{ONH}$, but that the laterality of ONH cannot reliably predict the degree of endocrinopathy present. ${ }^{2,8}$ Results provided here demonstrate no statistical difference in endocrine dysfunction for patients with bilateral ONH as compared to those with unilateral ONH ( $p$ 0.05 based on exact chi-square results from $2 \times 2$ tables). One explanation for this difference in study results may be the small sample size provided here. Of the 37 patients with documented ONH and OCT Spectralis imaging, only 8 patients were recorded to have endocrine dysfunction. Additionally, although all patients with $\mathrm{ONH}$ received orders for blood hormone levels to be drawn, $43 \%$ percent of patients had incomplete test results.

As previously identified, many patients with ONH have an associated cognitive delay that can make evaluation via OCT difficult. ${ }^{18}$ Upon chart review, only one patient in this study was noted to be nonverbal. The extent or presence of cognitive delay was not otherwise identified. As such cognitive delay was not evaluated in patients as part of this study. It is not unreasonable to assume that patients with severe cognitive delay would be less likely to successfully complete OCT testing. In this retrospective analysis, a larger contributor to subject exclusion was young patient age. All patients under the age of 4 years old on which OCT testing was attempted were unable to successfully complete this testing.

The greatest limitation of this study lies in the small sample size. Because of this, interpretation of results as relationship trends provides the greatest insight. Future studies with larger numbers of subjects will help to further illuminate the trends identified here. Obtaining RNFL thickness data through the use of the Heidelberg OCT Spectralis was also a challenge in children under 4 years, many of whom lack the understanding and ability to focus their vision during OCT imaging. Similar difficulties exist for patients with extremely poor visual acuity (i.e., minimal to no light perception) as they are unable to appropriately fixate their eyes as the instrument takes measurements. This may continue to be a challenge in 
future studies when using the OCT Spectralis RNFL thickness results as a marker of disease severity. Another limitation lies in operator error while evaluating a patient's best-corrected visual acuity. As with any interaction with children, there is room for error in determining the bestcorrected visual acuity when relying on a child's interpretation of the vision chart.

Although this study has a small sample size, which limits the conclusions that can be made from statistical tests, trends within the results indicate that best-corrected visual acuity is related to RNFL thickness at the optic nerve head. Odds ratios for the prevalence of nystagmus also point to RNFL thickness as a contributing factor. With further study, these trends have the potential to characterize ONH severity by objective measurement of RNFL thickness at the optic nerve head and clinical outcomes.

\section{Disclosure}

The authors report no conflicts of interest in this work.

\section{References}

1. Zeki SM, Dutton GN. Optic nerve hypoplasia in children. $\mathrm{Br}$ J Ophthalmol. 1990;74(5):300-304. doi:10.1136/bjo.74.5.300

2. Kaur S, Jain S, Sodhi HBS, Rastogi A. Optic nerve hypoplasia. Oman J Ophthalmol. 2013;6(2):77-82. doi:10.4103/0974-620X.116622

3. Jan JE, Robinson GC, Kinnis C, MacLeod PJM. Blindness due to optic-nerve atrophy and hypoplasia in children: an epidemiological study. Dev Med Child Neurol. 1977;19(3):353-363. doi:10.1111/ j.1469-8749.1977.tb08372.x

4. Patel L, McNally RJQ, Harrison E, Lloyd IC, Clayton PE. Geographical distribution of optic nerve hypoplasia and septo-optic dysplasia in northwest England. $J$ Pediatr. 2006;148(1):85-88. doi:10.1016/j.jpeds.2005.07.031

5. Garcia-Filion P, Epport K, Nelson M, et al. Neuroradiographic, endocrinologic, and ophthalmic correlates of adverse developmental outcomes in children with optic nerve hypoplasia: a prospective study. Pediatrics. 2008;121:e653-e659. doi:10.1542/peds.2007-1825
6. Pang Y, Frantz KA. Comparison of Heidelberg Retina Tomograph with disc-macula distance to disc diameter ratio in diagnosing optic nerve hypoplasia. Ophthalmic Physiol Opt. 2016;36:317-323. doi:10.1111/opo.12274

7. Pang Y, Frantz KA, Roberts DK. Association of refractive error with optic nerve hypoplasia. Ophthalmic Physiol Opt. 2015;35:570-576. doi:10.1111/000.12229

8. Qian X, Fouzdar Jain S, Morgan LA, et al. Neuroimaging and endocrine disorders in paediatric optic nerve hypoplasia. Br J Ophthalmol. 2018;102:906-910. doi:10.1136/bjophthalmol-2017-310763

9. Siatkowski RM, Sanchez JC, Andrade R, et al. The clinical, neuroradiographic, and endocrine profile of patients with bilateral optic nerve hypoplasia. Ophthalmology. 1997;104:493-496. doi:10.1016/ S0161-6420(97)30286-3

10. Sorkin JA, Davis PC, Meacham LR, et al. Optic nerve hypoplasia: absence of posterior pituitary bright signal on magnetic resonance imaging correlates with diabetes insipidus. Am $J$ Ophthalmol. 1996;122:717-723. doi:10.1016/S0002-9394(14)70492-1

11. Heidelberg Engineering GmbH. Spectralis HRA+OCT User Manual: Software Version 5.7. Carlsbad, California: Heidelberg Engineering, Inc; 2013.

12. Mohney BG, Young RC, Diehl N. Incidence and associated endocrine and neurologic abnormalities of optic nerve hypoplasia. JAMA Ophthalmol. 2013;131(7):898-902. doi:10.1001/jamaophthalmol.2013.65

13. Weiss AH, Kelly JP. Acuity, ophthalmoscopy, and visually evoked potentials in the prediction of visual outcome in infants with bilateral optic nerve hypoplasia. J AAPOS. 2003;7(2):108-115. doi:10.1016/ S1091-8531(02)42004-6

14. El Beltagi TA, Bowd C, Boden C, et al. Retinal nerve fiber layer thickness measured with optical coherence tomography is related to visual function in glaucomatous eyes. Ophthalmology. 2003;110 (11):2185-2191. doi:10.1016/S0161-6420(03)00860-1

15. Yamagishi N, Anton A, Sample PA, et al. Mapping structural damage of the optic disk to visual field defect in glaucoma. Am J Ophthalmol. 1997;123:667-676. doi:10.1016/S0002-9394(14)71079-7

16. Skarf B, Hoyt CS. Optic nerve hypoplasia in children: association with anomalies of the endocrine and CNS. Arch Ophthalmol. 1984;102:62-67.

17. Kelly JP, Baran F, Phillips JO, Weiss AH. Optical coherence tomography in optic nerve hypoplasia: correlation with optic disc diameter, nerve fiber layer thickness, and visual function. J Neuro-Ophthalmol. 2018;38:312-319. doi:10.1097/WNO.0000000000000596

18. Kelly JP, Phillips JO, Weiss AH. VEP analysis methods in children with optic nerve hypoplasia: relationship to visual acuity and optic disc diameter. Doc Ophthalmol. 2016;133:159-169. doi:10.1007/ s10633-016-9566-6
Clinical Ophthalmology

\section{Publish your work in this journal}

Clinical Ophthalmology is an international, peer-reviewed journal covering all subspecialties within ophthalmology. Key topics include: Optometry; Visual science; Pharmacology and drug therapy in eye diseases; Basic Sciences; Primary and Secondary eye care; Patient Safety and Quality of Care Improvements. This journal is indexed on PubMed

\section{Dovepress}

Central and CAS, and is the official journal of The Society of Clinical Ophthalmology (SCO). The manuscript management system is completely online and includes a very quick and fair peer-review system, which is all easy to use. Visit http://www.dovepress.com/ testimonials.php to read real quotes from published authors. 